\title{
Sex, Class, and History: An Experiment in Teaching Economics in an Interdisciplinary Setting
}

\section{Ora Freedman}

\begin{abstract}
The author reports on various aspects of teaching economics in an interdisciplinary, team-taught course, including reflections on a unique experiment in teaching economics to nonmajors. By the incorporation of selected topics of gender economics into the interdisciplinary course about the changing economic statuses of women throughout history, the students are introduced to the fundamentals of economic thinking and encouraged to become economically literate. Faced with the constraints of no prerequisites and the presence of two instructors at all classes, the author implements pedagogical models of teaching adopted from the education field to achieve a desirable level of comprehension and integration. The author outlines the course design, the challenges, and suggestions about how to improve the course.
\end{abstract}

Keywords: gender economics, interdisciplinary teaching, teaching economics to nonmajors

JEL codes: A20, A22, J16

Teaching economics to freshmen in an interdisciplinary setting provides a unique way of exposing students to the field of economics. The opportunity to develop and teach such a course in my college stemmed from the creation of a new honors program at the college. The cornerstone of the program is a series of interdisciplinary, team-taught seminars designed, in part, to fulfill general education requirements. ${ }^{1}$ The college provides support to instructors from different disciplines for developing and teaching an honors seminar. ${ }^{2}$ In designing these seminars, the instructors face several external constraints. ${ }^{3}$ In addition to fulfilling a general education requirement, they include no prerequisites, and these seminars cannot be counted toward a major. The college encourages the honor students to take these seminars in their freshman and sophomore years.

I found the prospects of developing and teaching an interdisciplinary, teamtaught course appealing. It provides a vehicle to expose our brightest students to the field of economics. Teaching honors students can be a rewarding experience, presumably because they are more motivated to learn and have greater academic

Ora Freedman is a professor of economics at Stevenson University (e-mail: f-freedm@mail.vjc.edu). Copyright @ 2008 Heldref Publications 
aptitude. Implementing nontraditional teaching methods may improve the teaching outcome and, finally, exposure to other disciplines may contribute to personal and professional growth.

Developing and teaching an interdisciplinary, team-taught course also has its drawbacks. Pedagogically, there is the challenge of both demonstrating interdisciplinarity and enabling the students to make connections between the disciplines. There are philosophical differences between disciplines in their underlying assumptions, methods of analyses, and valuation. Finally, instructors, especially seasoned ones, have their own teaching styles; they are comfortable with their own grading systems and methods of commanding the class.

In this article I present an example of teaching economics in an interdisciplinary fashion. I begin with a description of the course design, which explains the goals and objectives for the course and tools of assessing students' learning outcomes. In the Discussion and Reflection section, I focus on evaluating the effectiveness of using the interdisciplinary approach in teaching economics and enabling a meaningful integration, particularly given the lack of prerequisites and the time constraints. I then reflect on the experience of team teaching and report about students' perceptions of the course. I conclude with some suggestions to improve the quality of the course, from the initial design, teaching techniques, and assessment procedure.

\section{COURSE DESIGN}

My co-instructor and I developed and taught the interdisciplinary (economics and history) course titled Sex, Class, and History: Examining Women's Economic Status Throughout History, in the fall 2004 semester as an honors seminar. The goal in designing the course was to find a meaningful way of integrating the disciplines of economics and history and to foster an in-depth analysis of the issues outlined in the syllabus. The challenges were threefold. First, there were no prerequisites, yet an interdisciplinary content implied a level of integration possible only with a solid grasp of each discipline (Caviglia-Harris 2003; Ruwe and Leve 2001). Second, both instructors were required to attend all classes. The challenge, therefore, was to clearly define the role of each instructor during class meetings. Finally, we were strongly encouraged to use nontraditional teaching and assessment tools.

Both instructors prepared a list of concepts that we wanted included in the syllabus, and although we trusted each other's judgment with regard to those concepts, we were not in a complete agreement on how to achieve the integration without compromising the teaching of discipline-specific topics. The economic literature has not addressed comprehensively the issue of teaching economics in an interdisciplinary fashion. One exception was the model presented by CavigliaHarris (2003). In her model, economics was presented and taught as a separate module and time was set aside for interdisciplinary discussions.

Our course, however, was conceptually different. We envisioned weaving the two disciplines together throughout the semester. Economics provided a basis for discussion and analysis of historical events, and therefore it was necessary to construct an appropriate pedagogical framework of integration. We found a 
more in-depth discussion of the pedagogy of interdisciplinary teaching methods in the education literature. One model in particular, that of Fogarty (1991), fit our conceptual framework. Fogarty described 10 different models of integrating curriculum. ${ }^{4}$ In designing the seminar, we chose the following three models: the sequenced model, the shared model, and the integrated model. In the sequenced model, each discipline-specific topic is taught separately, but the order in which the topics are taught provides an understanding of the connection between the topics. The shared model is one where the two disciplines share some concepts. Class discussion, then, begins with the shared concepts and extends to the different disciplines. In the integrated model, the focus is on a particular theme, and the disciplines are brought in as tools to examine and analyze the theme. In designing our course, we used all three models. We began with the sequenced model, as a way of introducing the interdisciplinary approach to the topics discussed, and moved on to the shared and the integrated models, respectively. As the semester progressed we used a model that exhibited a greater degree of integration.

The course was composed of four units. The first unit was devoted to teaching some basic economic concepts, and therefore I took the role of the lead instructor. The objective of the unit was to teach the students how to think like economists. More specifically, it was to familiarize the students with the economic paradigm, which enabled them to evaluate and value historical events. First, I introduced some basic concepts of neo-classical economics, including scarcity, opportunity cost, comparative advantage, and supply and demand. I used the traditional graphs in explaining these concepts, focusing on the supply and demand graphs and the production possibilities frontier. Second, I illustrated and reinforced these concepts by using examples from the field of gender economics. I employed selected chapters from Women and the Economy (Hoffman and Averett 2005) and The Economics of Women, Men and Work (Blau, Ferber, and Winkler 2001) for this purpose. The following examples illustrate this approach.

I introduced the concepts of demand and supply in the product market by experimenting with Coke bottles I brought to class. The class created a market for the Coke bottles. Prior to discussing demand schedules, I asked the students for their willingness to pay (demand) for the bottles and recorded the answers. In the same fashion, prior to discussing the supply schedule, I asked the students for their willingness to sell the bottles to the instructors (supply). A considerable amount of time was spent on practicing a movement along, and a shift of, the demand and supply schedules. The next session started with a seemingly friendly discussion about marriages. I asked the students what they were looking for in their future mates. A lively discussion about love followed our carefully planned questions. I then introduced and explained Becker's model of supply and demand of marriages (as discussed in Hoffman and Averett 2005). The students found this application a fascinating extension of economics. They found the analogy between the market for Coke and the market for marriages intriguing and thought provoking. They began using the approach and vocabulary when analyzing the concept of the institution of marriages throughout history.

When explaining the concepts of comparative advantage and benefits from trade, I chose an example of a team of two students who had to produce a PowerPoint 
presentation about some current economic event. One student was an economics major, and the other one was a computer science major. We discussed how with specialization (the economics major researching the topic and the computer science major preparing the PowerPoint presentation), their joint grade would be higher than if each did both tasks. This example was appealing because the students related to it very easily because they had produced PowerPoint presentations throughout their high school career. Once the students seemed to grasp the concept, I introduced a substitution and said, let us now substitute a husband and a wife team for the students' team and a well-run household for a very good PowerPoint presentation. The students, then, were encouraged to think of how to apply the model of comparative advantage to discuss the household division of labor.

The theme of the second unit was a survey of history from ancient times to the Middle Ages. The objective of the unit was to examine historical events through women's perspectives. Therefore, my co-instructor took the lead for class discussions.

We focused our discussion on the status of women in different societies and in different time periods. Our goal was to reach a level of integration where students could examine women's status, using the economic paradigm taught earlier. For example, when examining women's inferior status, students were able to use the model of comparative advantage in explaining how the traditional division of labor may have been efficient for the household unit but left women without economic power.

Pedagogically, we employed the sequenced model in teaching the first two units, which implied a very basic level of integration and therefore was most appropriate for the first part of the semester.

The third unit focused on industrialization. This unit was different from the first two units in our pedagogical approach. The economic thinking of that time (i.e., the writings of Adam Smith and Karl Marx) was an integral part of the historical events. The goal was to reinforce how the economic thinking of that time grew out of the economic conditions and the social construct and how economic thinking influenced women's status. Because there is a considerable overlap between the disciplines, we attempted to employ the shared model. Discussion of Karl Marx's articles, for example, lent itself to a natural convergence of the two disciplines.

We were able to demonstrate a greater degree of interdisciplinarity in this unit for two reasons. First, both instructors felt equally qualified to lead class discussions, and, as a result, class discussions became more lively, and interdisciplinary connections were more evident. In addition, the period of industrialization encompassed the emergence of market economies and neoclassical economics, enabling the students to gain a better and broader perspective of economics.

We devoted the last unit to discussing contemporary economic issues in light of historical events. Our goal was to empower the students to make the interdisciplinary connections by debating current issues such as affirmative action and comparable worth. This unit included a series of debates, where the students took the lead in preparing and arguing their positions. In preparing for the debate, the students had to engage in independent research that drew on class discussions of historical events and economic models. 
After students experienced an in-class integration, as had been demonstrated by the instructors in the third unit, we let them take the lead in the last unit. Our hope was to be able to reach the integrated level (Fogarty 1991), where the students could critically examine an issue by employing an interdisciplinary approach.

\section{ASSESSING LEARNING OUTCOMES}

The learning outcomes for this course were twofold: demonstrating an understanding of the topics presented in a discipline-specific context (e.g., explain the effects of an increase in women's average wage rate on the division of labor within the household) and demonstrating the ability to integrate the disciplines. To effectively assess these learning outcomes, we implemented different assessment tools. We required the students to take turns in leading class discussions and to provide summaries of the assigned readings. We chose this assessment tool for a number of reasons. We did not assign any textbook for the course. Instead, we composed an extensive reading list, and we wanted to make sure the students read and comprehended these assigned readings on a basic level. In addition, we hoped that, by forcing the students to be active participants right from the start, we would be more successful in setting a seminar-type atmosphere from the beginning. Students also took a midterm exam and a final exam. The exams included both disciplinespecific and integrated questions and essays. The following examples illustrate this approach. The first question tested the students' ability to explain and interpret the discipline-specific concepts, and the second question tested their ability to integrate the disciplines.

\footnotetext{
1. Briefly explain (and draw the graph of) Becker's model of supply and demand for marriage. Over the last 35 years, the percentage of women who never married, in the United States, has increased from about 20.6 percent to 31 percent. Could Becker's model be used to explain this trend? Illustrate on the graph. Use the following data (the data include labor force participation rates, fertility rate, educational attainment, marriage and divorce rates, and age at first marriage) to support your answer.

2. Briefly outline the feminist critique of neoclassical economics. In your opinion, does neoclassical economics provide an adequate explanation for the change in women's status from ancient times to the present time? (You may choose to concentrate on a shorter period of time if you wish). Support your argument with examples.
}

Debates provided a way of assessing the students' ability to go beyond class discussions. The class debates took place in the last two weeks of the semester. The debates provided us with the means to assess the students' ability to engage in independent research and their ability to critically examine an issue by taking an interdisciplinary approach.

Furthermore, the debates allowed us to assess oral communication and clarity of presentation. The following is an example of an assigned debate topic: Should affirmative action be considered in hiring and promoting practices? To facilitate a good debate and ensure that all students were active participants in all debates, we divided the class into three groups; pros, cons, and the panel that examined the evidence and rules on the matter. We never discussed the topic of affirmative action in class. We expected the students to research the topic and the historical events that led to the original ruling on affirmative action. We instructed them to apply 
economic theories discussed in class to support their argument, either in support of or against affirmative action.

\section{DISCUSSION AND REFLECTION}

Teaching economics in an interdisciplinary, team-taught format is very different from teaching principles of economics or gender economics. I had to be careful not to treat this course as an accelerated or watered-down course in principles of economics or a gender course.

My goal was to provide the students with some basic tools to enable them to think like economists and talk like economists. More specifically, by focusing on a few concepts of economics, I was able to devote more time to examples and practice. I made the depth versus breadth tradeoff in favor of depth. Because this course did not count towards a major or a minor in economics, I had the freedom to teach as little or as much economics as I saw fit.

I chose to concentrate on a few principles of economics: the concept of opportunity cost, the production possibilities frontier, and supply and demand (for both product and factor markets). I found that, although the students understood these concepts intuitively, the format did not allow for sufficient mastery of the graphical representation of the concepts. The strength of this course was that, like a foreign language course, it provided the students with a new language that enabled them to view the world in a new way. The students were able to use this new language to analyze historical events. They began using terms and phrases such as tradeoff, cost-benefit, opportunity cost, and incentives in discussing choices made by women in different time periods. Requiring the students to talk like economists changed the way in which they were thinking. Using words such as incentives and opportunity cost when evaluating women's choices and women's behavior throughout history helped the students to think like economists. Understanding the concepts of rational decisionmaking and thinking at the margin were very useful when class discussion turned to Adam Smith and the invisible hand. The students were able to appreciate Adam Smith's theory and successfully compare it to that of Karl Marx.

Achieving a coherent and meaningful integration between the disciplines was a challenge throughout the semester. In particular, applying neoclassical models to time periods when market economies did not exist proved to be very difficult (if not impossible). Some of the challenges of integrating the disciplines were alleviated in the second part of the semester. The students were able to apply the newly learned economic terminology to historical events that occurred after the emergence of market economies. As the students compared and contrasted the theories of Karl Marx and the feminist critique with the theory of neoclassical economics, the interdisciplinary connections became more evident. This kind of analytical thinking prepared the students for the last unit, in which they had to debate a new topic. By that time, they were comfortable in using economic phrases to support their arguments. They defended their positions by applying basic economic principles they had practiced using throughout the semester.

Employing nontraditional assessment tools showed mixed results. For the most part, the debates proved to be an excellent assessment tool. The students were 
enthusiastic about debating the issues and devoted a considerable amount of time to research. The quality of the research, as measured by the type of sources the students used, was not strong. The students relied mostly on popular internet Web sites and not scholarly journals. Requiring the students to lead class discussions while providing summaries of the readings was an effective method for the history readings but not for the readings in economics. The students lacked sufficient background to successfully comprehend the material by reading alone. I would, therefore, not recommend using this assessment tool in the future.

\section{TEAM TEACHING}

Teaching styles vary, in part, because of the underlying philosophies of the disciplines. The economic paradigm is based on constructing abstract and general models designed to explain human behavior. In contrast, the history discipline tends to concentrate on many facts and details. These differences lend themselves to differences in teaching styles and may hinder the flow from one unit to the next. In our course, these differences were evident in the first part of the semester, where, at times, it seemed we were cutting and pasting two separate courses. We did not foresee this problem because we did not take the time to sit in on each other's classes in a previous semester. The way we attempted to resolve the perceived discontinuity was by assuming the role of an interested student. The instructor who was not the lead instructor participated by asking questions and interjecting his or her thoughts. We hoped that even though the delivery style was different, this type of interaction would reinforce the connections between the disciplines and would demonstrate to the students how to think in an interdisciplinary fashion. For the most part, the students enjoyed this interaction, and they joined in the discussion.

Instructors' active participation in all classes required close collaboration. In fact, collaboration was an essential ingredient of the interdisciplinary, team-taught course. From the initial stages of brainstorming the idea to writing the syllabus and teaching, collaboration required openness to different ideas and different teaching methods. It required the ability to compromise and to let go of total ownership of the course. Typical problems we encountered included the inability (or wish) to compromise on the material covered, the differences in instructional and grading style, ${ }^{5}$ and the difficulty in co-leading class discussions. Of equal importance was the difficulty in creating or fostering chemistry between the two instructors (if it did not naturally exist). In the education literature, we found suggestions to help mitigate these potential problems. Letterman and Dugan (2004), for example, proposed the following ideas: observing each other's teaching prior to committing to team teaching, becoming familiar with the co-instructor's discipline, and creating a very detailed syllabus lesson.

\section{STUDENTS' EVALUATIONS}

In addition to the standard college-wide end-of-the-semester student evaluation form, we also distributed an open-ended questionnaire. The questions specifically addressed the unique structure of the course and its effectiveness. According to 
these evaluations, students, for the most part, enjoyed the uniqueness of the course. Most of them took a course or two in history in high school, so they were comfortable with the concepts and requirements. None of the students had taken economics prior to this course, and they were more apprehensive about the content and requirements. Even though there was minimal use of graphs as a way of explaining the concepts, the students found the graphs that were used to be confusing at times. However, in terms of value added, students felt that studying economics in this fashion provided them a new way of relating economics to real life. The students noted that they learned a lot about economics and that they enjoyed the experience.

With regard to the extent of the level of integration, students' opinions were mixed. They found that the team-teaching experience enhanced their appreciation of both fields, and they enjoyed the integration of the disciplines. They were disappointed, however, by the amount of discipline-specific memorization required. Although this sentiment was expressed mainly with regard to the history part, it underscores the underlying problem of attempting to achieve a meaningful integration with no prerequisites.

\section{CONCLUSIONS AND RECOMMENDATIONS}

Attempting to teach economics in the traditional way in the context of an interdisciplinary setting may prove to be frustrating because of a perception that there is insufficient class time to fully develop a discipline-specific body of knowledge. Therefore, instructors may feel that students are not appropriately prepared to contribute in a meaningful way. Employing a different teaching technique of focusing on teaching students a few concepts of economics thinking and how to apply these concepts in examining other disciplines achieves several goals. First, it exposes the students to the economic way of thinking, the economics paradigm, and another way to view the world. Second, it encourages students, who may otherwise not be interested in economics, to consider taking more economics courses. Third, it encourages the students to consider economics as they examine an array of issues.

In the future, when teaching a similar interdisciplinary course, I would consider focusing on fewer issues and providing a more in-depth examination of these topics. More specifically, I would advocate including only the eras of preindustrialization to contemporary time. In terms of the course design, that would eliminate the second unit and add, instead, a more in-depth examination of the industrial period, as well as the examination of neoclassical economics and the critique of neoclassical economics. Both instructors would then be more familiar with each other's discipline-specific concepts and, therefore, would be better able to provide a more tightly woven course. In addition, by limiting the number of topics discussed in class, the instructors would be able to foster appreciation of the specific disciplines and a more meaningful way of integrating these disciplines. Pedagogically, adopting the different levels of integration (Fogarty 1991) proved very successful in achieving the goal of the interdisciplinary approach to teaching the course, and I would recommend following this structure.

I would also recommend the following modifications to the learning assessment tools. First, provide more guidance for conducting scholarly research when 
preparing for the debates. Second, eliminate the student-led class discussions for the economics part and instead use the more traditional problem sets that emphasize verbal and graphical explanations. This should reduce the anxiety that students express about using graphs.

Overall, teaching economics in an interdisciplinary fashion proved to be a worthwhile endeavor for all stakeholders, and I would recommend this approach as one more way of attracting students to the field of economics.

\section{NOTES}

1. In developing the college honors program, the faculty strongly supported the need for innovative and nontraditional teaching approaches. Our faculty believed that interdisciplinary, team-taught seminars would foster a greater degree of analytical thinking and the ability to make interdisciplinary connections. The belief in the potential pedagogical benefits stemming from interdisciplinary, team-taught courses is well grounded and documented in the education literature. The benefits of interdisciplinary, team-taught courses include promoting critical thinking, the ability to integrate disciplines, and an appreciation of the complexity of diverse issues (Davis 1995; Borg and Borg 2001; Cowen, Ewell, and McConnell 1995). Interdisciplinary teaching promotes active learning (Lattuca, Voight, and Fath 2004) and, as pointed out by Newell (1994), develops writing and thinking skills and fosters tolerance and an open mind toward other people's opinions and perspectives.

2. The college provides a modest stipend for faculty to develop and teach an honors seminar. In addition, teaching an honors seminar counts (in teaching load) as one course per instructor, even though there are two instructors teaching the same course.

3. The guidelines for developing and teaching an honors seminar include the following: Two instructors from different disciplines would teach the course; both instructors would be present in all classes; the course would have no prerequisites and would only count toward fulfilling a general education requirement; and the instructors are encouraged to implement innovative (nontraditional) assessment tools.

4. Fogarty's (1991) 10 models of integrating the curriculum can be classified into three categories: integrating curriculum within single disciplines, across several disciplines, and within and across learners. We focused on the different levels of integration within the category across several disciplines. Although this category outlines five different models of integration, we found three models applicable for our course: the sequenced model, the shared model, and the integrated model.

5. In terms of grading assignments, we devised a system whereby each instructor graded his or her own discipline-specific question, and both of us graded the integrated questions and the debates. The final grade on a particular assignment was the average of the two instructors' grades.

\section{REFERENCES}

Blau F. D., M. A. Ferber, and A. E. Winkler. 2001. The economics of women, men, and work. Englewood Cliffs, NJ: Prentice-Hall.

Borg, J. R., and M. O. Borg. 2001. Teaching critical thinking in interdisciplinary economics courses. College Teaching 49 (Winter): 20-26.

Caviglia-Harris, J. 2003. Introducing undergraduates to economics in an interdisciplinary setting. Journal of Economic Education 34 (Summer): 195-203.

Cowen, M. A., B. C. Ewell, and P. McConnell. 1995. Creating conversation: An experiment in interdisciplinary team teaching. College Teaching 34 (4): 127-31.

Davis, J. R. 1995. Interdisciplinary courses and team teaching: New arrangements for learning. Phoenix, AZ: Oryx.

Fogarty, R. 1991. Ten ways to integrate curriculum. Educational Leadership 49 (October): 61-65.

Hoffman, S. D., and S. Averett. 2005. Women and the economy. Boston: Pearson, Addison Wesley.

Lattuca, L. R., L. J. Voight, and K. Q. Fath. 2004. Does interdisciplinarity promote learning? Theoretical support and researchable questions. Review of Higher Education 28 (Fall): 23-48.

Letterman, M. R., and K. B. Dugan. 2004. Team teaching a cross-disciplinary honors course. College Teaching 52 (Spring): 76-79.

Newell, W. H. 1994. Designing interdisciplinary courses. Interdisciplinary Studies Today: New Directions for Teaching and Learning 58 (Summer): 35-51.

Ruwe, D., and J. Leve. 2001. Interdisciplinary course design. Clearing House 74 (Jan/Feb): 117-19. 
Copyright of Journal of Economic Education is the property of Heldref Publications and its content may not be copied or emailed to multiple sites or posted to a listserv without the copyright holder's express written permission. However, users may print, download, or email articles for individual use. 